\title{
Parliamentary Information Visualization as a Means for Legislative Transparency and Citizen Empowerment?
}

Investigating the Rationale, Aspirations, Feasibility and Effectiveness of PIV Efforts.

\author{
Aspasia Papaloi ${ }^{*}$, Dimitris Gouscos** \\ * Laboratory of New Technologies in Communication, Education and the Mass Media, Faculty of Communication and Media \\ Studies, University of Athens, Greece, apapaloi@media.uoa.gr \\ **aboratory of New Technologies in Communication, Education and the Mass Media, Faculty of Communication and Media \\ Studies, University of Athens, Greece,gouscos@media.uoa.gr
}

\begin{abstract}
The objective of this article is to highlight the contribution and importance of parliamentary information visualization (PIV) with a view to legislative transparency and citizen empowerment. The constant appeal for parliamentary openness regarding information on laws and bills and accountability of elected representatives calls for transparency in parliamentary procedures and at several areas of parliamentary informatics, in order to enhance democratic control and reestablish constituents' trust. On the other hand, the provision of easy to understand and analyze information plays a central role to the achievement of transparency. In this respect, this paper provides an overview of the characteristics and capabilities of information visualization that can contribute to delineating the institutional, but also technical possibilities and constraints of achieving legislative transparency. On the basis of this overview, it is attempted to highlight some causal relationships between parliamentary openness, legislative transparency and parliamentary information visualization, and discuss the potential and limitations of PIV not only in terms of technical solutions but also with respect to human factors and political aspects that need to be considered as further determining the success or failure of PIV efforts. In this line of thought, the concluding section of the article provides a discussion on the strengths, weakness, opportunities and threats that can be identified for parliamentary information visualization, as well as on dimensions and specific checkpoints that can be used to evaluate the effectiveness of PIV efforts, as regards the end objective of citizen empowerment.
\end{abstract}

Keywords: Information Visualization (IV), Parliamentary Information Visualization (PIV), legislative openness, legislative transparency, transparency indicators, citizen empowerment, visualization effectiveness, Parliamentary Informatics (PI), eParliament.

T

he famous quote "a picture is worth a thousand words" is able to summarize the meaning of how an image is capable of communicating our words and messages. The field of contemporary visual communication encompasses a wide spectrum of disciplines ranging from linguistics, neuroscience and psychology, to communication, human-computer interaction ( $\mathrm{HCl})$ and aesthetics; an interdisciplinary field that examines how our vision and brain perceives the visual stimulus, how this is interpreted and expressed, how we interact with the existing messages and, finally, what are the offerings of this kind of interaction.

Nowadays, the effort to communicate information is of utmost importance given that (a) the confluence of data received from the web is of high-density, (b) available documents contain too much information, (c) our time is limited and, sometimes, (d) information may be unclear or ambiguous. Information visualization (InfoVis or IV) is a means of facilitating this procedure in a dynamic way taking into account the constraints regarding the nature of information and visualization, respectively. Current research regarding visualization of public information, especially with regards to transparency, unfortunately focuses mostly on the technical side rather than the institutional or political aspects of this effort.

However, this discussion becomes even more interesting and opens a new research field when it is linked to legislative transparency and the visual representation of parliamentary information, 
namely "information and statistics about individual legislators; particular legislative proposals; votes thereon; text of legislation"(Wikipedia, 2013).

In addition to this, parliamentary information visualization (PIV) offers a broad spectrum of issues to investigate and discuss due to the fact that it encapsulates three components: (i) the issue of information provision with a view to informing citizens; (ii) the issue of transparency in technical terms; and (iii) the issue of legislative transparency as a means of empowering citizens. Concepts such as the Right To Know, the Right To Information (RTI), Access To Information (ATI),Freedom of Information (FOI), openness, accountability, empowerment but also those of timeliness, accuracy and comprehension are among those highlighted in the draft text of "Open Government Standards/Principles", as well as in the "Declaration on Parliamentary Openness".

These initiatives, not to mention the latest World e-Parliament Report of 2012, demonstrate vividly the need for presenting and explaining the legislative process to citizens in an explicit and comprehensible manner. To a further extent, openness is able to lead to transparency and, in the long run, to the accountability of legislators and the empowerment of citizens regarding their say at several stages of their participation in decision-making, according to each country's political system.

The article is divided in three parts, each focusing on a different set of issues. The first part of the article departs from an overview of IV features in order to set the canvas for the contribution of IV to gains in knowledge, communication and collaboration. Subsequently, these features are discussed as to their contribution in outlining the basic characteristics of openness and transparency, but also in extracting transparency indicators, which are important for the measurement of the availability and accessibility of the information provided. This discussion leads to highlighting the contribution of IV to legislative transparency, with a view to an opened-up parliament concept. The last part of the article discusses these points with regards to their usefulness for PIV. Opportunities and constraints of visualizing parliamentary information are highlighted, whereas a direction of future work is outlined with respect to initiatives which implement visualization techniques related to Parliamentary Informatics.

\section{A Framework for Information Visualization}

\subsection{The Role of Visual Patterns and Structures for Information Visualization}

Taking a closer look at the numerous examples of visualizations or, otherwise called, visual representations, it can be concluded that they give the opportunity for browsing large amounts of information, seeking information, exploring relationships and even comparing the latter or following their evolution by isolating other factors or entities, in an easy to follow and systematic way. Ware (2004), mentions that the intelligence of people is not evolving without cognitive tools - in our case computers, networks and the World Wide Web. That is to say, "the world is the repository of the information needed to act" (Ballard, 1996, p. 111) and visualization serves this purpose by bringing the knowledge of the world to users by "presenting the data in such a way that the important and informative patterns stand out" (Ware, 2004, p. xxi), helping users categorize the incoming information, facilitating its connection with previous knowledge and helping build new connections and new knowledge.

Whereas knowledge is the end result of visualizations, IV has to do not only with the representation of information but also with the interaction leading to subsequent changes of this representation (Yi, Kang, Stasko \& Jacko, 2007). Moreover, due to this dynamic transformation visualizations are able to call for engagement, questions and disagreements at each stage of the visual representation by fostering collaboration and giving the sense of "where you might want to

\footnotetext{
${ }^{1}$ The "Open Government Standards/Principles" and the "Declaration on Parliamentary Openness" stem from civil society initiatives. Detailed information can be retrieved online at http://www.opengovstandards.org and http://www.openingparliament.org, respectively.
} 
go next" (Schrage, 2013). The following definition summarizes the essence of IV as "the use of computer-supported, interactive, visual representations of abstract data to amplify cognition" (Card, Mackinlay \& Shneiderman, 1999, p. 7) where abstract data "refers to (heterogeneous) data that has no inherent spatial structure" (Info-Vis Wiki, n.d.). Additionally Meadows (2003), talking about the art of interactive narrative, distinguishes among three forms of interactivity namely "acquiring of information, discovering additional information, and facilitating the distribution of that information among multiple people". As these points indicate, IV can serve as an intermediary between information and knowledge and has the potential to allow users engage in interactive participatory activities, known as collaborative IV.

Lengler and Eppler (2007) brought the theory and research agenda of visualization one step further by compiling a table of visualizations categorized by objective. Their classification distinguishes between Data Visualization, Information Visualization, Concept Visualization, Strategy Visualization, Metaphor Visualization and Compound Visualization. This assortment of IV approaches contains techniques such as timelines, flowcharts, clustering, cycle diagrams, loop diagrams, semantic networks, tree maps, parallel coordinates, radar chart cobwebs, and other (ibid.). In the periodic table of IV techniques that Lengler and Eppler propose, most of the techniques available promote, on top of their interactivity, critical thinking through which users "reduce complexity through analysis and synthesis" (ibid., p. 4). The cognitive process is discussed below in more detail. In particular, the importance of critical thinking in deliberative democratic processes and in forming empowered citizens lies at the heart of our discussion.

\subsection{Accessibility, Usability and Information Visualization}

Accessibility and usability guidelines, which are already in place for websites, are also related to the technical, cognitive and social requirements for IV. Moreover, this is to be expected, since both accessibility and usability and IV deal with the broader agenda of Human-Computer Interaction $(\mathrm{HCl})$.

According to the definition given by W3C (2012), accessibility refers to allowing people with visual, auditory, physical, speech, cognitive and neurological disabilities to achieve equal access and opportunity to information. Accessibility standards are also applicable for users that are not visually oriented and prefer other means of being informed (Card et al., 1999) and, of course, in the case of elder people. Requirements for accessibility further relate to design issues (including choice of colors, pictures, multimedia, contrast, and others), where there are clearly common grounds with IV. As McEachren et al. (2012) state, different visual variables are able to communicate differences in information through commonly understood metaphors, which is quite useful especially for the case of people with cognitive and neurological disabilities. IV techniques seem to be able to reach a "diverse, widespread, less technical audience" (Gershon \& Eick, 1997, p. 29) with different backgrounds, education, skills and needs. In this respect, IV techniques can also be considered to create an inclusive audience and help bridge, up to some extent, problems of digital divide.

The ease of use of IV techniques has to with the quality, efficiency and effectiveness of the user experience, as well as with the end satisfaction of the user. In particular, the dimensions to be considered for IV include "visual impact; clarity; perceived finishedness; directed focus; facilitated insight; modifiability; group interaction support" (Bresciani, Blackwell \& Eppler, 2008, p.1). Respectively, Bresciani et al. (2008) explain that the usability of IV needs to take into consideration the following factors:

- the degree of visualization attractiveness;

- the ease of comprehension without any particular cognitive effort;

- the degree at which contributions and modifications to the visualization are possible, as opposed to the case in which a visualization seems to be "a finished, polished product";

- the ability to direct attention to the principal item(s) of discussion; 
- the possibility of generating new insights;

- the possibility of modifications in the visualization items while the discussion evolves;

- the degree at which visualization facilitates or structures the interaction of a group.

As far as technical requirements are concerned, Card et al. (1999) suggest the use of open standards with a twofold purpose: (a) in order to avoid user frustration due to "misinterpreting displays" and "coming to incorrect conclusions";and also (b) as a common pattern of data representation.

Last but not least, the clarity of information is an issue of utmost importance and has a significant degree of difficulty to achieve. This difficulty basically stems from the fact that the information received in the form of a document contains many variables and is more often than not quite complex. Clarity of information has a number of technical, visual and cognitive aspects and, for this reason, "it is imperative to contextualize messages in terms of their purpose, scope, and time" (Eppler \& Bischof, 2011, p. 11).

The next section investigates in depth the cognitive usefulness of IV and attempts to outline its connection to other disciplines.

\subsection{Information Visualization at the Service of Knowledge, Communication and Collaboration}

IV is an interdisciplinary field and its techniques embrace both technical and cognitive issues. In order to better understand how an IV-based application amplifies cognition, it is necessary to discuss the processes of visual thinking, visual learning and visual communication.

From an IV standpoint, the process of thinking starts by browsing data without having a concrete goal or question in mind, which leads to the examination and exploration of data and ends by making new discoveries and gaining insight (Fekete, Wijk, Stasko \& North, 2008). Furthermore, Lengler et al. (2007) make a distinction between convergent and divergent thinking, meaning that this process results either in critical thinking or in the development of unique and creative responses to the issue that is faced. McLoughlin \& Krakowski (2001) and Constantine \& Lockwood (2002) state that visual thinking is a manipulating process rooted in instructive interaction and involving "(...) implicit guidance of the user by the user interface in order for the user to best learn how to use a system". "The structure, appearance, and behavior of the user interface taken as a whole provide all the needed help, guidance, and instruction" (Constantine et al., 2002, p. 2).

This approach corresponds to a number of technical issues for IV that according to Eppler et al. (2011) require:

- reduction of item number through structuring or grouping;

- focus on the essential relationships of the items;

- ability of an overview before drilling down to details;

- consideration of the possible changes.

Apart from "visual queries on information graphics", which partially enable the solution of the problem when seen, and the element "of non-visual information" evocation, namely evocation of verbal information and subsequent storage "to long-term memory" (Ware, 2004, p. 352), this part of visual thinking signals the transition to visual learning and to an interactive process based on "constructing connections between visual and verbal representations of a system"(McLoughlin et al., 2001, p. 128).

This procedure indicates that the implicit process of visual thinking leads to an explicit one and, additionally, to the amplification of cognition thanks to the encoding of the information; to the condensed searching and "monitoring of a large number of potential events"(Card et al., 1999, p. 16); to the enabling of inferences; to the visual organization of data based on structural relationships enhancing patterns; and finally to "the increasing of memory and processing resources available to the users" (ibid.). 
The end result of visual thinking and learning, therefore, is not just plain knowledge; communication, interaction and collaboration are also potentially enhanced. Additionally, an interactive visualization implies possible changes on the user interface and communication patterns. Here comes the field of knowledge visualization, that aims to exploit visual representations for the transfer of knowledge "in order to increase its speed and its quality"; "to further transfer insights, experiences, attitudes, values, premonitions, perspectives, opinions and predictions (...)"; to address knowledge at several levels ranging from "among individuals, from individuals to groups, and from individuals and groups to the entire organization" (Burkhard, 2004, p. 520; Eppler \& Burkhard, 2004, p. 4). In turn, this kind of knowledge and communication among users enables collaborative IV and collaborative knowledge work contributing to a further step of decision-making, beyond sheer problem-solving. Finally, as Bresciani and Eppler (2009) note, the benefits of collaborative knowledge sharing seem to reinforce not only individual learning and team performance but also enhance significantly the performance of organizations, which is crucial for legislatures.

As we have tried to highlight in this short overview, IV is a prerequisite to access of information, gain in insights and construction of new knowledge in order to further enable collaborative knowledge sharing. Especially nowadays, existing social networks and their possibilities seem to be a promising channel in connecting various groups at a social level and further encouraging collaborative information visualization. A recent study of Viégas and Wattenberg (2010) based on the "Many Eyes" public website, where anyone could upload and visualize data, resulted in engaging groups with different backgrounds as well as inexperienced users. Moreover, the completeness of data and the identification of original sources have enabled extraction of useful outcomes, based on reliable data and effectiveness of the overall process. Last but not least, visualization has revealed perspectives that the concerned parties had not planned. Efforts like this showcase the potential of IV to result in interactive environments that lay the grounds for a new discussion on openness, transparency and their correlations.

\section{Information Visualization at the Service of Transparency}

\subsection{Mapping Transparency and its Interrelations}

Transparency is a slippery term, having different meanings in different contexts; its meaning is quite interesting, however, when talking about parliamentary information. Special attention should be given in the discussion between transparency and openness due to the fact, as Bannister \& Connolly (2010) also claim, that both these concepts have interwoven meanings, yet they are not identical. In general terms, openness has to do with the availability and accessibility of information, whereas transparency is linked to the degrees of accessibility, visibility (Florini, 2007; Bannister et al., 2010) and reliability of information (Fox, 2007). One more characteristic could be added to this list for the aspects of transparency, namely the degree of achieving an inclusive audience, in line with the principles of accessibility. Transparency, according to this analysis, can be considered as a natural corollary of openness, "one form of operationalization of openness", that indicates "how openness is delivered or achieved" (Bannister et al., 2010, p.4). Taking a step further, in the context of legislatures, parliamentary transparency serves a twofold purpose, namely that of representatives' accountability and citizens' empowerment.

In an attempt to draw an analogy between this discussion of transparency, and the previous discussion on IV as an intermediary between information and knowledge, one could say that IV is related to openness, knowledge is related to empowerment and transparency can be placed in the center of such a concept map. In this respect, we would like to propose a set of relations between IV and openness, IV and transparency and, finally, IV and empowerment, with a view to outlining a set of indicators for legislative transparency and parliamentary information provision.

The difficulty in drawing a strict distinction between openness and transparency in relation to information provision is also encountered in the literature, which does not easily allow to distinguish 
which features belong to openness and which to transparency, especially with regard to parliamentary information. Nevertheless, we make an attempt to draw such a distinction based on the concepts and definitions put forward in the Declaration of Parliamentary Openness of the OpeningParliament.org forum, as well as on the draft Open Government Standards/Principles proposal of the Open Government Standards initiative, coordinated by Access Info Europe. Our proposal is visualized in Figure 1.
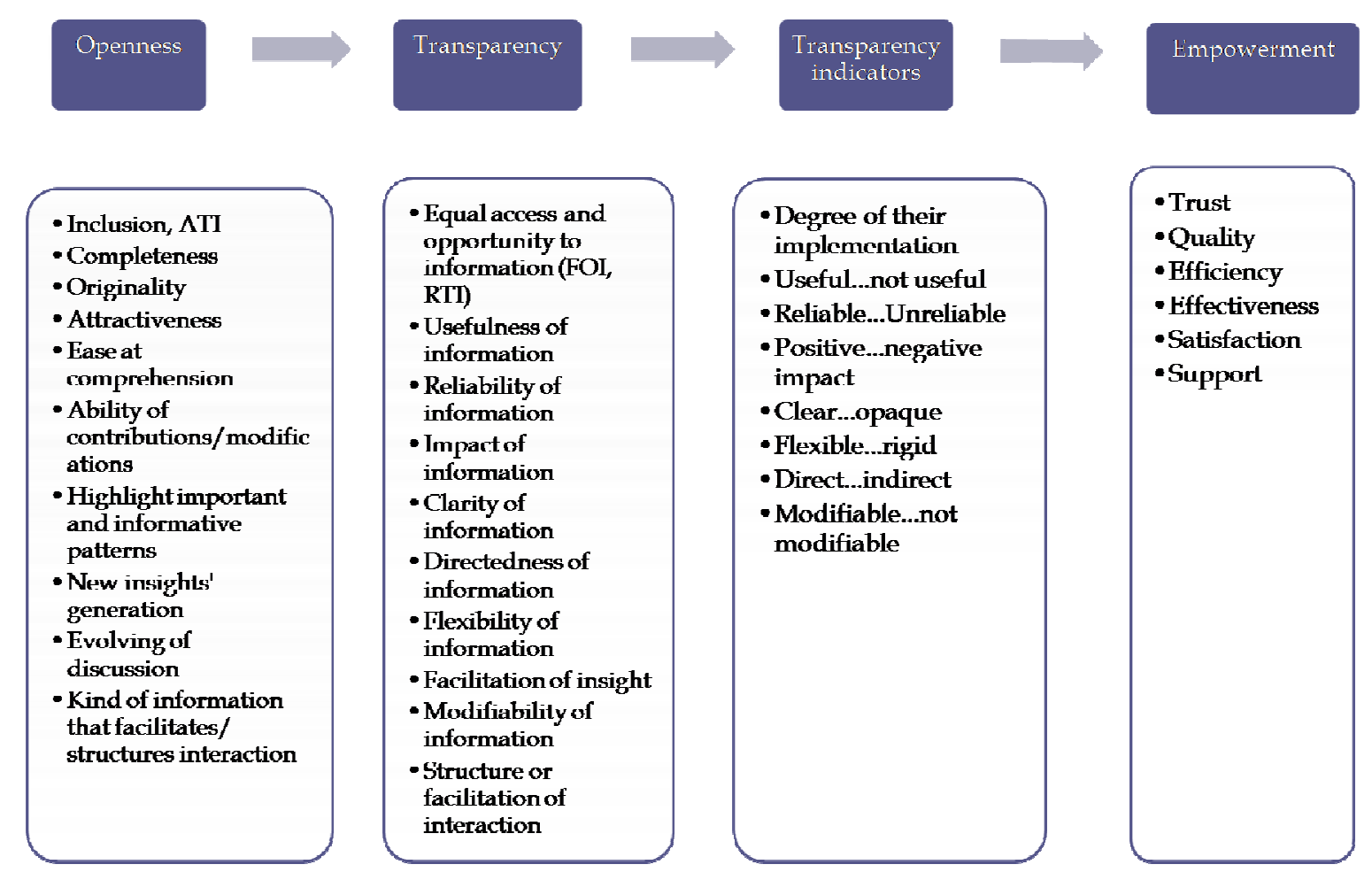

Figure 1. Interrelations between openness, transparency and empowerment

As depicted in Figure 1, our proposal attempts to draw a distinct agenda for transparency, as an end result of openness, and operationalize this agenda through a number of indicators having to do with the usefulness, reliability, positive impact, clarity, flexibility, directedness and modifiability of the information provided. Satisfaction of all these indicators, then, could enable users/citizens to gain not only insight but also enhance their critical thinking. What is more, empowerment of citizens' thinking and say can lay the grounds for enabling further demands for accountability on behalf of elected representatives.

As a last point, this discussion should also be considered in terms of human factors, especially when talking about IV. It is clear that transparency is not achieved by merely giving away information, but rather by the way this information is perceived through human understanding and interaction, "searching for both known and unknown information" (Gershon et al., 1997, p.31) and problem-solving. This subject, which goes beyond the scope of our current analysis, calls for further research into the perception of visual information provided for transparency purposes, at the cross-roads of IV, visual design and cognitive studies.

\subsection{Transparency, Information Visualization and Non-technical Aspects}

The potential of web-based IV techniques, as discussed in the previous section, to implement the indicators for transparency proposed in Figure 1 above is manifold. Firstly, an IV platform is able to provide information efficiently and effectively, which can satisfy users and support their interaction. Secondly, the quality of the IV and the information itself can build users' trust, to the 
extent that it is inclusive and enables inspecting several aspects of an issue. The issue of information quality, of course, varies according to the end users' perspective and depends on their point of view (Miller, 1996). The characteristics of timeliness, accuracy, relevance, coherence and validity of information are some significant dimensions regarding information quality. Besides the point of view and the degree of perception of each user, Miller (1996) also states that the management of information quality is a "continual process", which constantly changes depending on the needs and the technologies offered.

Consequently, the social, legal and institutional aspects of the analysis visualized in Figure 1 cannot be overlooked. Openness, transparency and empowerment are at the same time end results and processes that cannot exist in isolation from each other. Their correlation and the degree of their impact are determined by the various interested parties and stakeholders involved in their realization, namely politicians, senior officers, public servants, civil society initiatives, whistleblowers, Parliamentary Monitoring Organizations (PMOs). These characteristics, on the other hand, are also dependent upon the extent of Freedom Of Information and Right To Information provisions established in each country and embraced by each culture. Last but not least, the kinds of information that can be disclosed or need to remain classified also vary significantly in each country, according to the ways in which the issues of secrecy and privacy are regulated for citizens, but also for politicians and legislatures. IV may enhance or promote transparency but the process of opening data is not as simple as it might seem. This is explicitly outlined in the research of Janssen, Charalabidis \& Zuiderwijk (2012), which concludes that opening data does not necessarily lead to transparency, due to a significant number of barriers starting from a "no uniform policy for publicizing data" to "lack of ability to discover the appropriate data", barriers related to use and participation, as well as barriers related to legislation. These problems are also acknowledged by Wilson \& Linders (2011) examining the US 2009 Open Government Directive and stressing, among others, that "the guiding principles of collaboration, participation, and transparency are simply too broad, vague, lacking in scope, and insufficiently quantifiable to provide actionable guidance" without exempting the human factor from a policy formulation process. This discussion, extending beyond the scope of the present paper, gives rise to two points worth keeping in mind:

- As the results by Viégas et al. (2010) on the "Many Eyes" website show, an IV effort can reveal perspectives on top of the information visualized which politicians had not planned for, and this may be seen as a political danger. This, in turn, can generate the need for multiple levels of regulated information disclosure ranging from secrecy, opacity, obfuscation, full disclosure or divulge of information and, finally, privacy.

- Whereas ATI relates to openness and its characteristics, FOI and RTI belong to another sphere of discussion, with respect to the definitions and meanings of freedom and right. Staying focused on the political dimension, FOI implementation laws can be most crucial, demanding "time, money or personnel to easily organize information" and requiring not only political commitment but also the engagement of senior officers and public servants (Neuman \& Calland, 2007, p.191).

\subsection{Contribution of Information Visualization to Legislative Transparency}

The discussion, in the sections above, of the potential of IV applications to enable information transparency needs to be complemented with a discussion of the central role that information provision currently has for legislatures. This discussion can then lay the grounds for the potential contribution of information visualization to legislative transparency, as well as serve to introduce a concept of Parliamentary Information Visualization (PIV).

Indeed, information provision seems to be one of the most significant factors in order to enable transparency for legislatures. The latest World e-Parliament Report of 2012 gives a clear picture of the challenges that parliaments face in terms of communication with the citizens. The most important one is that of citizens' difficulty to familiarize themselves with the legislative process 
(United Nations, Inter-Parliamentary Union \& Global Centre for ICT in Parliament, 2012), whereas the top-three objectives for using ICT-based methods of communication are identified as informing citizens about policy and bills; explaining what parliament does; and engaging more citizens (ibid.).

Most of nowadays parliaments already operate with a significant degree of transparency regarding information provision according to their Constitution and Rules of Procedure. Still, this is not enough; information provision seems to be dependent on the political will and priorities of the administration that holds power every time (Wilson et al., 2011, Scholl \& Luna-Reyes, 2011). Moreover, legislative transparency must be examined as part of a system that includes other stakeholders such as the press, citizens, and lobbyists, as well as in accordance with the norms of the executive and judicial branches of power. As the research of Scholl et al (2011) shows, the extent of information provision regulates the balance, feedback and effect of each of these branches. In this context, what seems to be failing is that the top-level goal of informing citizens about policy and bills has to be achieved in an effective and simple way in order for parliaments to further develop citizen engagement. This argument is also shared by the majority of non-profit initiatives that implement ICT-based applications for informing citizens with respect to parliamentary operations.

The relation between visualization and transparency is outlined explicitly by the listing of the advantages of visualization by Ware (2004), according to which IV (i) "provides the ability to comprehend large amounts of data", (ii) allows to perceive patterns that are not anticipated and gives further and new insight, (iii) "enables problems with the data itself to become immediately apparent", thus serving quality control, and (iv) "facilitates understanding of both large and smallscale features of the data". These characteristics respond to the requirements for parliamentary openness and attest to the need for provision of parliamentary information, especially in the case of bills and long documents, through tools for Parliamentary Information Visualization (PIV). The importance of PIV approaches as a candidate solution for parliamentary transparency is also stressed through cases like the example of the Parliamentary Management System of the Asamblea of Madrid using semantic concepts for integration, sharing and reuse of legislative information. According to the literature, experience with this effort shows that "the automation of the parliamentary work is sometimes inefficient and difficult to solve by intelligent information systems" (Costilla, Palacios, Cremades \& Vila, 2005, p.142). This point, in our view, can serve as an argument in favor of less automated and machine-intelligence based approaches to provision of parliamentary information, focused more on visual representations of data that address the capabilities of human perception.

Still, creating an open parliament that allows and amplifies cognition over parliamentary information, legislative processes and procedures seems to be a difficult venture to carry out successfully. A holistic approach on IV, transparency and its interrelations can constitute the cornerstone of deliberative democracy, which is perceived as "an open, continuous and dynamic process" that enables the "perception and understanding of complex problems by citizens as well as the discovering of other aspects related to an issue" (Held, 2007, p.328).

\section{On the Feasibility and Effectiveness of Parliamentary Information Visualization}

The discussion over IV as regards to governmental and parliamentary data is an emerging research field. Rogers (2010) mentions some projects already implemented in the USA within the Open Government Agenda, with a view to promoting transparency, participation and collaboration. Moreover, other initiatives try to aggregate and present in a single database cases that promote transparency and categorize them according to the techniques and tools employed.

In technical terms, PIV may be feasible. Juxtaposing the discussion of the previous sections for the potential of IV against the requirements and objectives set out in the Declaration on Parliamentary Openness, and taking into account the distinctive nature of transparency, its correlations and limitations, the feasibility of PIV can also be argued through a SWOT analysis framework. 


\subsection{Some Strengths, Weaknesses, Opportunities and Threats for Parliamentary Information Visualization Efforts}

A factor that can be considered as strength in the quest for PIV is that IV advocates openness through a wide range of characteristics, such as open-source software; usability and accessibility; two-way interaction; and the ability to discover hidden aspects, all of which fall within the current agenda of Parliamentary Informatics.

A weakness for the PIV effort, on the other hand, relies on the fact that legislative information is not available in a format readily suitable for diffusion to the general public, especially in the case of documents such as bills or laws that contain a lot of detailed data, rules, exceptions and legal terminology; these difficulties, it should be noted, are strongly reminiscent of the barriers mentioned in the literature for the creation and adoption of open data.

On the contrary, an opportunity for PIV is offered, in our view, by the ability to visualize historical parliamentary or legislative information through time-lining techniques, giving to citizens some tangible evidence on the records of a parliament's operation.

Last but not least, as far as threats are concerned, we refer to the following two points from the work of Stray (2010) and his team, when they tried to visualize the Iraq War Logs:

- the actors who bear the responsibility of choosing what kind of details will be emphasized or omitted, are not necessarily favorable to transparency; and at the same time,

- the manner in which a visual representation enables a user to make correct inferences, is not always chosen as the most flexible one.

In this line of thought, it should not go unnoticed that contemporary media and channels are able to support IV-based applications and reinforce their interactive character. Social media, in particular, constitute a privileged platform for diffusing visualized parliamentary information along a large social network, which would allow a diverse audience not only to get informed, but also have its say in legislative decision-making.

\subsection{A Framework for Evaluating the Effectiveness of Parliamentary Information Visualization Efforts}

The variety of visualization methods and the different areas of concern to PI make difficult the evaluation of the effectiveness of PIV initiatives based on a set of commonly accepted criteria. Different PIV initiatives, for example, deploy different means for sharing parliamentary information with the public or gaining followers via social media, while other initiatives do not use such services at all. Still, the literature reports some research that tries to compile a checklist of assessment criteria for the effectiveness of PIV initiatives and also their contribution to empowerment of the public, based on a critical approach of Information Visualization.

In particular, Dörk, Feng, Collins \& Carpendale (2013) have proposed four dimensions for evaluating the effectiveness of information visualization efforts corresponding with the requirements proposed by Bresciani et al. (2008) and Card et al. (1999) for the usability of IV: connection, disclosure, plurality and empowerment. These dimensions stem from research on related domains and improvements in visualization research and are used by the authors as a "starting point for exploring issues of power in visualization", rather than a definitive classification. This choice is in line with the fact that not all aspects of visualization effectiveness are equally easy to incorporate in the design of IV applications and services, as the latter are always influenced by "the assumptions of their designer as well as the context of the viewer" (ibid). In particular:

- Connection is considered to be the most crucial aspect of a visualization, linking the issue visualized with the viewers (Dörk et al., 2013). If an issue is not engaging the viewers, the latter will most possibly not proceed to understand and explore the visualization. According to Kostelnick (2008, as cited in Dörk et al, 2013) this constraint is also dependent on the relevance of the issue visualized to the viewers' interests, as well as on the context, namely the time and place, of viewing itself. 
- Disclosure encompasses the designers' aspirations on the potential effects of the visualization. These effects invite 'the viewer into exchanges with the designer, reflections about the visualization, and engagement with an issue" (Dörk et al., 2013). Therefore, the disclosure potential of a visualization can be considered to co-operate in a synergistic way with its connection potential, both of these aspects positively contributing to viewer engagement.

- The plurality of a visualization, on the other hand, has to do with the ability of the visualization to provide access to all possible representations of the information visualized. In this respect, the dimension of plurality includes both "passive" aspects such as the types of perspectives emphasized or hidden, as well as more "active" aspects such as the provision of facilities and facets for the exploration of statistical and personal information.

- Contingency is one more dimension of effectiveness for information visualizations. This dimension implies the provision of flexible visualizations that can be better adjusted to offer unique user experiences. According to Dörk et al., such visualizations contribute at the same time to more engagement, as they "can engage viewers more deeply with a given issue and relate it to their life", as well as to more insight, enabling "for more unique and profound experiences and insights".

- Last but not least, empowerment is the objective and end result of a successful visualization. Empowering visualizations give power both to their creators and to their viewers as, on the one hand, they enable "visualization creators to let their voice be heard and perspective be seen"; whereas on the other they permit "viewers to question visual representations, utilize them to tell their own story, and shift from awareness to action" (Dörk et al., 2013). Still, in the strive for empowering visualizations, which often calls for the use of more complicated visualization tools and techniques, IV designers need to take into account a number of access impediments on the viewer side such as, among others, different viewer backgrounds, different literacy profiles as well as unequal access to technology.

Based on the framework by Dörk et al. (2013) for arriving at a set of concrete criteria to assess the effectiveness of parliamentary IV initiatives in particular, further work can focus on a number of characteristics that correspond to the IV effectiveness dimensions described above, as follows:

- On the connection dimension, characteristics that can be examined include (i) high-level views and broad perspectives of the visualization(s); (ii) provision of conceptual maps for connection with the viewer's centers of interest; as well as (iii) invitations to viewers for shaping the visualizations.

- On the disclosure and plurality dimensions, characteristics of particular interest include (i) invitations to the viewer for exchanging reflections about the visualization; (ii) accompanying articles and background information for the subject of the visualization; as well as (iii) the ability of viewers to reason on the issues visualized.

- As far as contingency dimensions are concerned, two particular characteristics can be considered of special importance: (i) the manner in which the data underlying the visualization are updated, as well as (ii) the regular refreshment rate for keeping these data up-to-date.

- Finally, assessment of the empowerment dimensions of PIV initiatives could place focus on providing viewers with facilities enabling to (i) add comments and links; (ii) subscriptions and alerts; (iii) printing, e-mailing, sharing the information provided through social media; (iv) programmatic access to the data visualized; as well as (v)creation of alternative visualizations by the viewers themselves.

\section{Concluding remarks and future work}

PIV initiatives try to prove their usefulness in many ways, at the same time being in need to encompass a lot of aspects in order to improve their effectiveness. The explicit intentions and scope of a PIV effort are of utmost importance. Determining the objectives of a PIV project in terms of serving information, promoting awareness or creating engagement are essentially different 
choices, which inevitably reflect on the overall policy of PIV efforts. These choices will define further the target group, the kind of visualization methods, the means for spreading and accessing the information provided by a PIV application. In this line of thought, designers need to determine their target audience and the needs and abilities of the latter, prior to starting the design of a platform and deciding on the means of access. The choice of the suitable visualization method is another important aspect, heavily influenced by the qualitative or quantitative nature of the data at hand.

Undoubtedly, PIV initiatives can contribute to legislative openness and to accountability to a certain extent. This expectation is further substantiated by the similarities of PIV objectives to the Declaration on Parliamentary Openness but also by many currently ongoing PIV initiatives, which focus on visualizing the activity, behavior and performance of MPs, MEPs as well as political groups and member-state countries.

On the other hand, PIV initiatives could fulfill the role of a mediator between the legislatures and all interested parties, including the public, civil society, NGOs as well as the media. Legislatures and parliamentary institutions have opportunities of collaboration with PIV initiatives and IV platforms at technical, institutional as well as political levels. Aspiring to actually enact this opportunity, on the other side, requires on behalf of parliaments a significant initiation and investment, and at the same time a paradigm shift away from closed institutions and towards open communities.

As the discussion in the previous sections shows, citizen engagement even with the aid of visualizations is a hard to reach objective. It requires an in-depth and constant commitment in terms of the enabler institutions, with the recruitment of teams that are acquainted with the legislative procedure and able to motivate and moderate public viewers to be further engaged. For the time being, parliamentary information visualizations are rather operating at an information provision, rather than engagement-building level, rather staying within than departing from the traditional agenda of Parliamentary Informatics.

In this line of thought, our future work is intended to focus on an overview of Parliamentary Informatics initiatives all over the world that attempt to implement IV applications. Such an overview is envisaged to be organized along the geography and type of institutions (i.e. legislatures, nonprofit, for-profit institutions) that pursue PIV efforts, and proceed by evaluating their scope and degree of success, with a view to seeking best practices that could be abstracted to a more general approach for Parliamentary Information Visualization.

\section{References}

Ballard, D.H. (1996). On the Function of Visual Representation. In K. Akins (Ed.), Perception (pp.111-131). New York: Oxford University Press.

Bannister, F. \& Connolly, R. (2010).The Trouble with Transparency: A Critical View of Openness in e-Government. Paper presented at "Internet, Politics, Policy 2010: An Impact Assessment". Retrieved December 3, 2012, from http://microsites.oii.ox.ac.uk/ipp2010/system/files/IPP2010 Bannister Connolly Paper.pdf.

Bresciani, S., Blackwell, A. \& Eppler, M. (2008, February). Choosing visualizations for collaborative work and meetings: A guide to usability dimensions (Darwin College Research Report No. DCRR-07). Cambridge: Darwin College, Cambridge University. Retrieved January 3, 2013, from http://www.darwin.cam.ac.uk/dcrr/dcrr007.pdf.

Bresciani, S. \& Eppler, M.J. (2009, November/December). The Benefits of Synchronous Collaborative Information Visualization: Evidence from an Experimental Evaluation. IEEE Transactions on Visualization and Computer Graphic, 15(6), 1073-1080. Retrieved April 19, 2013 from http://www.knowledgecommunication.org/pdf/IEEE\%20transactions\%20-Coll\%20Vis\%20-Bresciani\%20Eppler.pdf.

Burkhard, R.A. (2004). Learning from Architects: The Difference between Knowledge Visualization and Information Visualization. IV '04 Proceedings of the Information Visualization, Eighth International Conference, IEEE Computer Society Washington, DC, USA, 519-524. doi:10.1109/IV.2004.89.

Card, S.K., Mackinlay, J.D. \& Shneiderman, B. (1999).Readings in Information Visualization: Using Vision to Think. San Francisco: Morgan Kaufman. 
Constantine, L.L. \& Lockwood, L.A.D. (2002). Instructive Interaction: Making Innovative Interfaces Self-Teaching. Retrieved January 8, 2013, from http://foruse.com/articles/instructive.pdf.

Costilla, C., Palacios, J. P., Cremades, J \& Vila, J. (2005).e-Government: A Legislative Ontology for the 'SIAP' Parliamentary Management System. In M. Böhlen, J. Gamper, W. Polasek \& M. A. Wimmer (Eds.), E-Government: Towards Electronic Democracy, International Conference, TCGOV2005, Bolzano, Italy, March 2-4, 2005, Proceedings (pp. 134-146). Retrieved April 3, 2013, from http://link.springer.com/chapter/10.1007\%2F978-3-54032257-3 13\#page-1.

Declaration on Parliamentary Openness (2012). Retrieved December 26, 2012, from http://www.openingparliament.org.

Dörk, M., Feng, P., Collins, C. \& Carpendale, S. (2013). Critical InfoVis: Exploring the Politics of Visualization. In alt.chi 2013: Extended Abstracts of the SIGCHI Conference on Human Factors in Computing Systems. Retrieved September 1, 2013, from http://vialab.science.uoit.ca/wordpress/wp-content/papercite-data/pdf/dor2013a.pdf.

Eppler, M. \& Bischof, N. (2011, November). Complex to Clear: Managing Clarity in Corporate Communication. St. Gallen: Institute for Media and Communications Management, University of St. Gallen. Retrieved December 29, 2012, from http://www.visual-literacy.org/pages/documents.htm.

Eppler, M. \& Burkhard, R.A. (2004, July). Knowledge Visualization: Towards a New Discipline and its Fields of Application. Lugano: Università della Svizzera italiana. Retrieved January 3, 2013, from http://www.bul.unisi.ch/cerca/bul/pubblicazioni/com/pdf/wpca0402.pdf.

Fekete, J.-D., Wijk, J.J., Stasko, J.T. \& North, C. (2008).The Value of Information Visualization. In A. Kerren, J.T. Stasko, J.D.Fekete \& C. North (Eds.), Information Visualization, LNCS 4950, (pp. 1-18). Berlin Heidelberg: Springer-Verlag. Retrieved April 19, 2013, from http://www.win.tue.nl/ vanwijk/infovis springer.pdf.

Florini, A. (2007). The Right to Know: Transparency for an Open World. New York: Columbia University Press.

Fox, J.A. (2007). The uncertain relationship between transparency and accountability. Development in Practice, 17(4), 663671. Retrieved January 13, 2013, from http://dx.doi.org/10.1080/09614520701469955.

Gershon, N. \& Eick, S.G. (1997).Information Visualization. Retrieved December 29, 2012, from http://www.cs.duke.edu/courses/cps296.8/spring03/papers/GuestEditor'sInfoVisIntroduction.pdf.

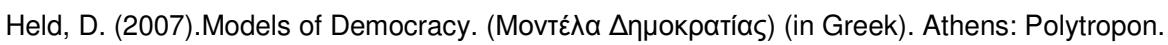

Info-Vis Wiki (n.d.). About Abstract Data. Retrieved January 3, 2013, from http://www.infoviswiki.net/index.php?title=Abstract data.

Janssen, M., Charalabidis, Y. \& Zuiderwijk, A. (2012).Benefits, Adoption Barriers and Myths of Open Data and Open Government. Information Systems Management (ISM), 29 (4), 258-268. Retrieved April 3, 2013, from http://www.tandfonline.com/doi/full/10.1080/10580530.2012.716740.

Kostelnick, C. (2008) The visual rhetoric of data displays: The conundrum of clarity. IEEE Trans. on Professional Communication 51, 1, 116-130.

Lengler, R. \& Eppler, J. M. (2007).Towards a Periodic Table of Visualization Methods for Management. In S. M. Alam, (Ed.), IASTED Proceedings of the Conference on Graphics and Visualization in Engineering (GVE 2007). Acta Press: Clearwater, Florida, USA. Retrieved December 26, 2012, from http://www.visualliteracy.org/periodic table/periodic table.pdf.

MacEachren, A.M., Roth, R.E., O’Brien, J., Li, B., Swingley, D. \&Gahegan, M. in press: Visual Semiotics \& Uncertainty Visualization: An Empirical Study.IEEE Transactions on Visualization \& Computer Graphics. Retrieved January 2, 2013, from http://www.geovista.psu.edu/publications/2012/MacEachren IEEE TVCG PrePub 2012 reduced res.pdf.

McLoughlin, C. \& Krakowski, K. (2001). Technological Tools for Visual Thinking: What Does the Research Tell Us? In eXplore 2001: a face-to-face odyssey: Proceedings of the Apple University Consortium Conference September 23-26, 2001. Retrieved February 4, 2013, from http://pandora.nla.gov.au/pan/25630/200207050000/auc.uow.edu.au/index29fbe.html?conf/conf01/page 7.html mainFrame.

Meadows, M.S. (2003).Pause \& Effect: The Art of Interactive Narrative. Indianapolis: New Riders.

Miller, H. (1996). The Multiple Dimensions of Information Quality. Muhlenberg College Allentown. Retrieved February 4 , 2013, from http://www.muhlenberg.edu/depts/abe/business/miller/mdiqual.html.

Neuman, L. \& Calland, R. (2007).Making the Law Work: The Challenge of Implementation. In A. Florini (Ed.), The Right to Know: Transparency for an Open World (pp.179-213). New York: Columbia University Press.

Open Government Standards (n.d.). Draft Open Government Standards/Principles. Retrieved February 2, 2013, from http://www.opengovstandards.org/.

Rogers, S. (2010, February 24). Information Access and Data Visualization Key to Government's Transparency Agenda [TIBCO Spotfire's Business Intelligence Blog]. Retrieved February 1, 2013, from http://spotfire.tibco.com/blog/?p=1816. 
Schrage, M. (2013, March 26). The Question All Smart Visualizations Should Ask [Harvard Business Review Blog Network]. Retrieved April 14, 2013, from http://blogs.hbr.org/schrage/2013/03/the-question-all-smart-visualizations.html.

Scholl, H. J. \& Luna-Reyes, L. F. (2011, September 26-28). Transparency and Openness in Government: A System Dynamics Perspective. In E. Estevez \& M. Janssen (Eds.), ICEGOV 2011, Proceedings of the 5th International Conference on Theory and Practice of Electronic Governance, Tallinn, Estonia (pp. 107-114). New York: ACM.

Stray, J. (2010, December 10). A full-text visualization of the Iraq War Logs. Retrieved February 1, 2013, from http://jonathanstray.com/a-full-text-visualization-of-the-iraq-war-logs.

United Nations, Inter-Parliamentary Union \& Global Centre for ICT in Parliament (2012). World e-Parliament Report 2012, New York: United Nations. Retrieved December 26, 2012, from http://www.ictparliament.org.

Viégas, F. \& Wattenberg, M. (2010). Case Study: Many Eyes. In D. Lathrop \& L. Ruma (Eds.), Open Government: Collaboration, Transparency, and Participation in Practice (pp. 249-256). Beijing: O' Reilly.

Ware, C. (2004).Information Visualization: Perception for Design. Amsterdam: Morgan Kaufmann.

W3C (2012, August 31). Designing for Inclusion. Retrieved January 17, 2013, from http://www.w3.org/WAl/users/Overview.html.

Wikipedia (2013, January 17). Parliamentary Informatics. Retrieved January 17, 2013, from http://en.wikipedia.org/wiki/Parliamentary informatics.

Wilson, S. C. \& Linders, D. (2011, February 8-11). The Open Government Directive: A Preliminary Assessment. In Proceedings of the2011iConference, Seattle, Washington (pp. 387-394). New York: ACM.

Yi, J.S., Kang, Y., Stasko, J.T. \& Jacko, J.A. (2007).Toward a Deeper Understanding of the Role of Interaction in Information Visualization. Retrieved January 3, 2013, from http://www.cc.gatech.edu/ john.stasko/papers/infovis07interaction.pdf.

\section{About the Authors}

Aspasia Papaloi

Aspasia Papaloi has been a civil servant at the Greek Parliament since 2002 and she is currently working at the IT and New Technologies Directorate. She holds a B.A. in German Literature and Language (1999), a MA in ICT Management (2006) and for the time being she is a research fellow of the Laboratory of New Technologies in Communication, Education and the Mass Media (Faculty of Communication and Media Studies, University of Athens). Focal point of her PhD research is the field of e-parliaments with regard to applications promoting transparency and citizen participation.

Dimitris Gouscos

Dimitris Gouscos is Assistant Professor with the Faculty of Communication and Media Studies of the University of Athens and a research fellow of the Laboratory of New Technologies in Communication, Education and the Mass Media, where he contributes to co-ordination of two research groups on Digital Media for Learning and Digital Media for Participation. His research interests include applications of digital communication in open governance, participatory media, interactive storytelling and playful learning. More details available on webpage http://www.media.uoa.gr/ gouscos. 